\title{
O historiador, o macaco e a centaura: a "história cultural" no novo milênio
}

SER GE GRUZIN SK I

\section{D ialogando com um macaco e uma centaura}

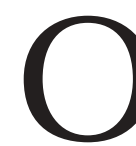

QUE PODE SER a história cultural hoje? Talvez possamos fazer a pergunta a dois amigos com os quais mantenho diálogo há vários anos e que me acompanharam em muitas conferências e viagens. Trata-se do macaco O zomatli e da centaura O cyrhoe. Eles vivem na cidade mexicana de Puebla, numa casa antiga chamada "C asa del $D$ ean", sobre um afresco pintado no fim do século XVI.

0 macaco 0 zomatli é de origem pré-hispânica e pode ser identificado pelo seu brinco. 0 macaco era um dossignos do cal endário ritual asteca e corresponde ao dia onze do calendário divinatório, estando associado à boa fortuna e à alegria, ou ainda à vida licenciosa. A centaura, por sua vez, chama-se 0 cyrhoe, filha do centauro Chironte. Dela se diz que "revelava os segredos do destino". O u seja, tanto a centaura como o macaco são seres encarregados de anunciar o destino. Entre uma e outro podemos observar uma flor, que parece ser de poyomatli, um alucinógeno utilizado pelos índios antes e depois da Conquista, difundido entre espanhóis, mestiços e mulatos. A pesar das distâncias culturais gigantescas, podemos observar a conivência estabelecida entre a semideusa do paganismo grego e o deus ameríndio que compartilham dos meios - a flor - de conhecer 0 porvir. N ão pode haver então melhores guias para tecer conjecturas so bre o que deverá ser a "história cultural" neste milênio.

\section{Etnocentrismos. A análise do afresco nos obriga a sair duma visão europocêntrica e etnocêntrica da $\mathrm{H}$ istória}

$\mathrm{H}$ oje, os historiadores da Europa continuam manifestando pouca curiosidade pelo passado e pela historiografia que excedem as fronteiras da Europa ocidental, e às vezes mesmo as fronteiras da sua própria nação. Q uanto aos especialistas da história mundial, estes tenderam a elaborar sua visão do mundo a partir da Europa ocidental ou de problemáticas que provinham da história deste continente. Por isso, na Europa e sobretudo na França costumamos chamar de americanistas os que estudam a história da América, enquanto os historiadores 
com " $h$ " maiúsculo são os que se dedicam à história da França ou duma Europa ocidental de preferência nórdica.

Frente ao conservadorismo europeu e francês, a denúncia do europocentrismo tornou-se muito comum nos Estados U nidos. D esde os anos de 1980, nas universidades deste país, os estudos culturais e estudos pós-coloniais multiplicaram as suas críticas contra o europocentrismo da história e das ciências sociais em geral. D enunciavam e denunciam uma história que só seria a projeção do 0 cidente, de suas categorias e de suas ambições em relação ao resto do mundo.

$\mathrm{N}$ a verdade, o etnocentrismo não pode ser reduzido ao europocentrismo. A presença da centaura grega nos afrescos mexicanos nos lembra que não nos podemos contentar com a análise da realidade local, neste caso, a história dos índios da N ova E spanha combinada com a história da sociedade colonial. Contudo, os especialistas do M éxico muitas vezes limitam os seus horizontes ao território nacional, ou seja, a uma invenção do século XIX, esquecendo a península ibérica, a Europa e quase sempre o resto do continente americano. Porém, outras centauras visitaram o Peru colonial no tempo em que sereias circulavam na América portuguesa...

\section{A história comparada}

Para limitar o etnocentrismo e ampliar os nosso horizontes, a história comparada pareceu uma alternativa possível. $M$ as as perspectivas que propõe podem ser enganosas. A seleção dos objetos que têm de ser comparados, dos quadros e dos critérios, as perguntas, as mesmas grilles de interpretação continuam sendo tributárias de filosofias ou de teorias da história que muitas vezes já contêm as respostas às questões do pesquisador. No pior dos casos, a história comparada pode aparecer como uma ressurgência insidiosa do etnocentrismo.

Além disso, no campo da "história cultural", como comparar culturas se as mesmas são entidades que remetem mais à nossa tradição antropológica do que a qualquer realidade histórica atual ou passada? 0 termo "cultura" tomou tantos sentidos que se tornou inutilizável. H á sentidos diferentes para a antro pologia, a história, os medias, a administração, as organizações internacionais... M as a palavra "cultura", sobretudo, mantém a crença - consciente ou não - de que existiria um conjunto complexo, uma totalidade coerente, estável, com limites precisos e que seria capaz de condicionar, de regular os comportamentos dos grupos e dos indivíduos.

Porém, as nossas críticas à história comparada são outras. $M$ uitas vezes, as empresas que a inspiraram tiveram pouca continuidade. Penso, por exemplo, no caso das tentativas realizadas entre o Peru e o M éxico e no ensaio pioneiro de Sergio Buarque de $\mathrm{H}$ olanda, o qual partia de uma comparação entre a colonização espanhola e a portuguesa, uma obra tão brilhante quanto isolada no panorama da produção latino-americana. 


\section{Connected histories}

Convém perguntar se o historiador pode escapar às fronteiras sem escolher a via da história comparada. L imitar-me-ei a aportar uma resposta pessoal inspirada pelo meu itinerário de pesquisador. $\mathrm{N} o$ início, seguia uma linha de pesquisa que pouco tinha a ver com esta preocupação. $M$ as o estudo dos fenômenos de aculturação no M éxico colonial nunca deixou de me colocar frente a processos que pertenciam, ao mesmo tempo, a dois mundos distintos, como no caso do afresco de Pueblo, que reúne elementos do passado pré-hispânico com elementos da Antigüidade européia.

D e um modo geral, a análise das imagens e das mestiçagens permitiu-me observar configurações que articulavam de maneira complexa elementos oriundos da E uropa e de outras partes do mundo, os quais podiam aproximar-se em pontos total mente inesperados. L onge das visões dual istas - que costumam opor o $O$ cidente aos outros, os espanhóis aos índios, os vencedores aos vencidos -, as fontes nos revelam paisagens misturadas, muitas vezes surpreendentes e sempre imprevisíveis. É precisamente o caso do encontro entre O cyrhoe e O zomatli. $\mathrm{N}$ ão se trata, no entanto, de comparar a mitologia greco-romana com a ameríndia. $M$ as de refletir sobre o enigma da ligação que nos apresenta, ou melhor dito, que nos impõe a pintura.

Parece-me que a tarefa do historiador pode ser a de exumar as ligações históricas ou, antes, para ser mais exato, a de explorar as connected hi storiesse adotamos a expressão proposta pelo historiador do império português, Sanjay Subrahmanyam. 0 que implica que as histórias só podem ser múltiplas - em vez de falar de uma $\mathrm{H}$ istória única e unificada com " $h$ " maiúsculo. E ssa perspectiva permite também a observação de que estas histórias estão ligadas e que se comunicam entre elas. D iante de realidades que convêm estudar sob diversos aspectos, o historiador tem de converter-se numa espécie de eletricista encarregado de restabelecer as conexões internacionais e intercontinentais que as historiografias nacionais e as histórias culturais desligaram ou esconderam, entaipando as suas respectivas fronteiras. As que dividem Portugal da Espanha, por exemplo, ou as que separam a A mérica espanhola da portuguesa são típicas deste bloqueio. Várias gerações de historiadores escavaram entre estes países fossos tão profundos que atualmente custa muito entender a história comum a estes dois países, impérios e subcontinentes.

\section{O utros obstáculos}

As retóricas da alteridade opõem, todavia, outros obstáculos tão temíveis como o peso das historiografias nacionais. $C$ abe ao historiador encontrar, sob as diferenças cultivadas pelas tradições locais e pelas visões de inspiração antropológica, continuidades, conexões ou simples passagens, muitas vezes minimizadas, quando não radicalmente excluídas da análise. $\mathrm{H}$ oje há muitos estudos sobre as povoações indígenas na América espanhola enquanto pouco se escreveu sobre os 
grupos mestiços e as mestiçagens. Assim, é preferível falar do O utro em vez de analisar os espaços intermediários nos quais este $O$ utro se encontra e se mescla. O afresco poblano do macaco e da centaura nos apresenta o olhar duplo de um pintor índio sobre o seu próprio passado e aquele dos vencedores, mitológico, um passado distante mas já objeto a ser apropriado. N ão se trata do tema já bastante comum do olhar europeu sobre o índio, tampouco se trata de mundos distintos: O zomatli é o macaco antigo revisitado por um pintor cristianizado, enquanto a centaura é uma criatura reinterpretada por um artista cujos antepassados pintavam serpentes com plumas.

Cabe acrescentar que o interesse pela micro-história, ou pela microetnohistória, também influenciou o olhar do historiador e que al guns pesquisadores acabavam "esquecendo" o contexto geral ao focalizarem o particular. Há estudos de este afresco que só consideram o local índigena, ignorando as referências a outros espaços muito mais distantes, como os do Renascimento europeu e da pintura maneirista italiana. A presença da centaura $O$ cyrhoe nos obriga a deixar a cidade de Puebla, a sair da N ova E spanha e do continente americano para cruzar o Atlântico e chegar até a I talia dos grotescos. O zomatli e 0 cyrhoe nos lembram que estas três abordagens, nacional, culturalista e microhistórica podem contribuir para descontexualizar os objetos de estudo dos lugares aos quais pertencem.

\section{O s mundos da M onarquia católica}

Ozomatli e $O$ cyrhoe encontraram-se no M éxico em 1585. M as em que mundo foram pintados? A que mundo pertenciam? Concretamente, em que escala e em que espaço deve intervir o "historiador-eletricista" para analisar os contatos dos quais falava Pierre Chaunu ou "os recobrimentos" estudados por Fernand Braudel? 0 exercício pode ser feito a partir de uma base local e quase microscópica: é o que fazemos ao analisar os afrescos pintados pelos índios mexicanos no fim do século XVI. Porém, a pesquisa deve ser estendida a horizontes muito mais amplos, que não seriam definidos em função de recortes contemporâneos, mas tendo em conta conjuntos políticos com ambições planetárias que se constituíram em momentos dados da história.

Em nossos trabal hos temos encontrado algumas destas configurações históricas. É o mundo que permite a um macaco mexicano e a uma centaura grega encontrarem-se e dialogarem numa cidade como a $\mathrm{N}$ ova E spanha. Este mundo não só associa regiões e reinos europeus, como também vários continentes para constituir um quadro político que os contemporâneos chamavam de M onarquia católica. E sta fórmula se aplicava ao conjunto de reinos agrupados sob o poder do rei Felipe II a partir de 1580, quando a união das duas coroas (portuguesa e espanhola) acrescentou às possessões de C arlos V Portugal e seu império.

Este grande império pode ser estudado de diversas maneiras. U ma delas é a política, já que se trata de uma construção dinástica. A M onarquia católica foi 
também o berço de uma primeira "economia-mundo", que suscitou estudos bem conhecidos e de grande relevo nos anos de 1970. Porém, estes trabalhos negligenciaram outros aspectos igualmente importantes, como, por exemplo, a constituição das primeiras burocracias operando numa escala planetária, burocracias que tinham estreitas ligações com a I greja, por causa do padroado português e do patronato espanhol.

0 destino de Salvador de Sá (1602-1686) ilustra bem o alcance que os mais altos funcionários podiam ter fora de seu território. Salvador de Sá foi governador do Rio de J aneiro a partir de 1637 e encomendero - senhor de terras e indígenas - em Tucumã. A sua mãe era uma espanhola, filha do governador de C ádiz. Q uanto a Salvador, este se casou com Catalina de Velasco que era sobrinha de L uis de Velasco vice-rei do M éxico e do Peru. Viveu seis anos no Prata, viajou às minas de Potosí e ficou fascinado pela prata peruana. $\mathrm{N}$ a guerra contra a $\mathrm{H}$ olanda, propugnou pela reconquista de Angola, desembarcou em $L$ uanda e expulsou os flamengos.

Caberia lembrar as redes internacionais constituídas pelas ordens religiosas, pelos jesuítas e pelos cristãos-novos. As manifestações literárias, plásticas e musicais da dominação filipina revelam que a Europa dos $\mathrm{H}$ absburgos desenvolveu uma determinada arte, chamada maneirista. Pela primeira vez, um estilo europeu obteve difusão internacional já que prosperou simultaneamente em três continentes. Basta um olhar sobre 0 afresco mexicano do macaco e da centaura. E stas dimensões múltiplas não fazem da M onarquia católica um "sistema cultural" nem uma civilização. $M$ as estão demais imbricadas umas nas outras para que 0 historiador se limite a abordar a M onarquia só em termos políticos ou dinásticos.

Portanto, enquanto muitos historiadores costumam preocupar-se em inventar e construir novos objetos definindo territórios e cronologias, a M onarquia católica forma uma realidade no espaço e no tempo que não precisa ser constituída. Essa preexistência não significa que os historiadores tenham espontaneamente adotado o território do império como campo de observação. M uitas vezes esta realidade gigantesca, por demais heterogênea e fragmentada para se deixar facilmente estudar, foi escamoteada nas abordagens hispanocêntricas ${ }^{1}$.

A Monarquia, porém, é um objeto apaixonante. Cobre um espaço que reúne vários continentes, aproxima ou conecta várias formas de governo, de exploração e de organização social, confronta de maneira às vezes bastante brutal tradições religiosas totalmente distintas. A M onarquia é o teatro de interações planetárias entre o cristianismo, o islã e o que os ibéricos chamavam de idolatrias, uma categoria que agrupava indistintamente os cultos americanos e africanos com as grandes religiões da Ásia. No seio deste espaço, instituições e práticas oriundas da Europa chocaram-se às de outros continentes. 0 impacto das instituições européias provocou efeitos en retour. Estabelecido em G oa, na cidade do M éxico e em Lima, o Santo O fício teve de controlar povoações e extensos territórios que transformaram as modalidades e 0 alcance da sua ação. 


\section{A primeira mundialização e a dilatação dos horizontes europeus}

$\mathrm{N}$ ão se trata apenas de definir um território. 0 território é indissociável de uma determinada problemática. A perspectiva da M onarquia católica permite abordar de maneira diferente a questão da modernidade, ao chamar a atenção para o conjunto hispano-português, que a tradição intelectual européia tem mantido longe do caminho desta modernidade. Trata-se, evidentemente, do caminho clássico que vai da I tália à I nglaterra, passando pela França e pela $\mathrm{H}$ olanda. Tal mudança de perspectiva tem efeitos paradoxais, já que, longe de confrontarmonos com uma E uropa meridional, arcaica e fossilizada, ela remete a um espaço planetário onde se produzem fenômenos que têm a ver de perto ou de longe com processos que atualmente chamamos de globalização e de mundialização.

A pesar de correr o risco de multiplicar anacronismos ou de fazer uma leitura retrospectiva das origens, proponho-me a analisar os mundos da M onarquia perguntando sobre o quê nos podem ensinar sobre a mundialização a partir das perspectivas que abrem. 0 macaco e a centaura continuarão, nesse sentido, a nos servir de guias.

U ma das caraterísticas da M onarquia católica é a sua presença em lugares tão afastados no espaço e na história como Salvador da Bahia, M éxico (1521), Lima (1536), M anila (1571), M acau (1557), G oa (1510) e L uanda (1576). Com os progressos da dominação espanhola e portuguesa, este expansionismo planetário impeliu para frente os horizontes europeus. Em todas as partes e quase ao mesmo tempo, nestas diferentes regiões do globo, os homens da M onarquia descobrem e enfrentam tradições e heranças que não têm ligação direta alguma com as da Europa ocidental.

Este fenômeno de planetarização manifesta-se por uma mudança sistemática de escala. Podemos observá-la em âmbitos tão diversos como o urbanismo, a literatura e o direito. Também podemos evocar a aparição de um público internacional de leitores com dimensões planetárias. O s livros impressos na península ibérica e na Europa cruzam os oceanos Atlântico, Pacífico e Índico. U ma obra, redigida para um vasto público, tão famosa e difundida como a Diana de M ontemayor, encontra os seus leitores tanto no Recôncavo Baiano como nas vilas das Filipinas espanholas. 0 mesmo acontece com as obras de 0 vídio, que já eram impressas na cidade do M éxico em 1577. 0 pintor índio de Puebla conhecia as $\mathrm{M}$ etamor fosescomo este $\mathrm{N}$ uno Fernandes, que o confessou à I nquisição em $1592^{2}$.

É interessante poder extrair do seu contexto europeu a história do livro - e por meio dele a do latim, do português, do castel hano - o reler da mesma maneira a história do direito e do urbanismo para medir a revolução que implicou a projeção planetária destas práticas e idéias européias. E assim romper com uma história cultural irredutivelmente europocêntrica. 
Porém, a difusão mundial dos saberes e dos imaginários da M onarquia representa apenas uma dimensão de um processo muito mais complexo. $\mathrm{N}$ ão podemos dissociá-lo do descobrimento simultâneo de outras línguas, outros saberes e modos de expressão. Pela primeira vez, os letrados de uma monarquia européia confrontaram-se com as principais civilizações do globo. É revelador que um franciscano como Bernardino de Sahagún estuda a filosofia moral dos índios do M éxico nos anos em que o agostiniano Juan González de M endoza examina a "filosofía natural y moral que se lê publicamente" entre os chineses. $\mathrm{N}$ a mesma época, os cronistas de Castela e de Roma examinam as pinturas pictográficas mexicanas e os livros da China enviados à Europa ${ }^{3}$.

$\mathrm{N}$ a mesma época multiplicam-se as comparações planetárias. U m historiador da C hina, Bernardino de E scalante, compara as cidades deste império com B ruges, Sevilha e Cádiz. N esta época, também os cronistas costumam introduzir paralel os totalmente inéditos entre as I ndias ocidentais e as I ndias orientais. No fim do século XVI, o globetrotter Pedro O rdoñez de C eballos compara a rede hidrográfica do $M$ ekong com a do Amazonas. $O$ português $M$ anuel Correia de $M$ ontenegro, revisor régio das impressões na U niversidade de Salamanca, compara o Brasil com as Í ndias de C astela: "naquelas não há mais do que ouro e prata enquanto no Brasil há também metais muito estimados e ademais outras muitas coisas proveitosas e saudáveis para a vida humana" ${ }^{4}$.

$M$ as com a dispersão dos ibéricos nos espaços da M onarquia, as perspectivas mudam e diversificam-se. D esenha-se uma mudança na percepção ocidental do mundo: a partir desta época, novas comparações podem ser feitas desde um ponto de vista situado em terras longínquas, que oferecem um novo quadro de referência, o qual substitui o quadro europeu ou ibérico. Por isso, o médico estabelecido no M éxico, J uan de Cárdenas, po de usar a fórmula "mais nas Í ndias do que em qualquer outra parte ou província do mundo". Esta mudança tem várias repercussões. Assim, por exemplo, na cidade do M éxico, na segunda metade do século XVI, elaborou-se uma visão propriamente americana da Ásia, ou seja, um "orientalismo" que se transplantou para o N ovo M undo sem perder as suas raízes ocidentais. O s moradores da N ova Espanha viam a Ásia espanhola e portuguesa com olhos novohispanos, ou seja, tanto como uma fonte de dinheiro como possibilidade para conseguir uma maior autonomia política e comercial em relação à M adri. Eles lisonjeavam-se de ser "o coração do mundo".

É de se perguntar se desde a Bahia e do Rio de J aneiro os brasileiros acostumados a visitar a África não desenvolveram também a sua própria visão deste continente, uma visão ligada aos seus interesses econômicos e à sua grande familiaridade para com Angola e C abo Verde. $O$ arquipélago de C apricórnio formava uma zona de intensas interações apoiadas sobre o circuito negreiro Lisboa-R io de J aneiro-L uanda-Buenos Aires. A mbrósio Fernandes Brandão considerava o comércio entre o Brasil, Angola, o Rio da Prata e o Peru mais importante do que as trocas com a metrópole ${ }^{5}$. Esta zona que descreve tão atiladamente L uis Felipe 
de Alencastro no Trato dos viventes, tem muito a ver com o M ar del Sur dominado pelos mercadores do M éxico, Peru e $M$ anila. C abe lembrar que as duas zonas econômicas se fortaleceram no período da M onarquia C atólica, logrando uma certa autonomia em relação à metrópole.

Estas novas perspectivas nos ensinam a sair do velho dualismo "Europa versusos outros" para pensar a Ásia ou a África a partir da América ibérica. 0 que complica ainda mais a tarefa do historiador, já que a relação América-Ásia no pode ser dissociada da relação América-África.

\section{M undialização e compressão das distâncias}

Seria errado reduzir o espaço da M onarquia católica ao do 0 cidente e de concebê-lo apenas em termos de expansão da civilização da Europa ocidental. Ao se expandir, o espaço ocidental integra, incorpora, anexa ou procura capturar outros espaços, sem porém absorvê-los. N esse processo, observamos uma compressão sem precedente das distâncias: 0 desconhecido torna-se familiar, 0 inacessível disponível, enquanto o longínquo aproxima-se de maneira espetacular. 0 vídio aparece em Puebla enquanto as pictografias mexicanas cobrem o teto da Galleria degli U ffizi. N um campo menos sofisticado, observamos o aumento de consumos extra-europeus para a Europa ocidental: ao mundo dos adeptos do tabaco, antes limitado a alguns grupos ameríndios da América, acrescentam-se os novos consumidores europeus.

A circulação das novas plantas e drogas e as transformações das farmacopéias européias são representativas destes movimentos que convergem sobre a península ibérica, em vez de partir dela. 0 testemunho de um médico de Sevilha, 0 doutor $\mathrm{N}$ icolas Bautista $\mathrm{M}$ onardes, permite 0 estudo da chegada das plantas ao porto de Sevilha e a sua difusão na península e na E uropa ocidental. A té permite estudar a "traçabilidade", ou seja, as distintas etapas da difusão e da transmissão do mundo ameríndio para o mundo europeu. Ao descrever a chegada da "raiz de M ichoacan", uma planta purgativa oriunda de Colima no M éxico, M onardes escreve:

Em tão grau tem-se estendido o uso da raiz que já é comum em todo o mundo, e se purgam com ela não só na Nova Espanha e províncias do Peru, mas na nossa E spanha e toda a I tália, Alemanha e Flandres. Eu tenho enviado grandes relações dela a quase toda a Europa, assim em latim como na nossa língua.

A circulação das plantas medicinais não só estabelece laços entre a Europa ocidental e a América espanhola. 0 utros saberes e plantas chegaram em Lisboa vindos das terras da Asia. Em 1563, Garcia d'O rta publicou em G oa a sua obra mestra, Coloqui os dos simples e drogas he cousas mediçinais da I ndia. 0 texto se difunde rapidamente em C astela. Q uatro anos depois, em 1567 C harles de l'E cluse publica uma versão latina em Antuérpia. Em 1593, outra versão do texto de 
Garcia d'O rta sai das imprensas flamengas, acompanhada pelo texto da obra do médico sevilhano $\mathrm{N}$ icolas $\mathrm{M}$ onardes. Assim, no coração editorial da M onarquia católica, ficam reunidos os novos saberes oriundos da América espanhola e da Ásia portuguesa ${ }^{6}$.

\section{A mundialização e o choque dos tempos}

0 estudo dos mundos da M onarquia católica leva a interrogar sobre o tema dos tempos e das temporalidades. A presença ibérica se traduz pela imposição sistemática da referência ao tempo ocidental e cristão, já que a colonização dos tempos acompanhou a do espaço em todas as partes. M as a história foi muito mais complicada: lembremos o pequeno macaco do afresco de Puebla, esta encarnação do tempo cíclico ameríndio, cooperando com a centaura, vestígio de outro tempo, pré-cristão, reinterpretado pelos leitores da Idade M édia e do Renascimento que o transformaram em tempo mítico.

O tempo ocidental não é apenas uma maneira de calcular o passo dos dias e das horas. É também uma concepção do passado e uma possibilidade de prever o futuro: a astronomia e a astrologia são as ciências que permitem estes prognósticos. Enfim, e sobretudo, o tempo é o ritmo imposto ao ano pelo calendário litúrgico. Esta unificação do tempo aparece como uma das características da M onarquia. $\mathrm{N}$ a sua $\mathrm{M}$ onarchia di Spagna, o calabrês Tommaso Campanella lembra que a missa é celebrada a cada meia hora sobre to da a extensão da M onarquia católica.

Porém, a imposição do tempo europeu toma uma forma bastante distinta quando experimentado a partir de um território americano ou asiático. Publicado no M éxico alguns anos depois do tratado de Campanella, o $R$ epertorio delos tiempos é um livro de astronomia, astrologia e história escrito pelo cosmógrafo alemão H einrich M artin. Nesta obra, o autor integra a cronologia da Nova E spanha à cronologia européia e à mundial: o tempo do vice-reinado americano aparece conectado ao tempo do Peru espanhol, da Inglaterra de H enrique VIII e de M aria Stuart, ou com o tempo das Filipinas. Esta integração pode ser acompanhada a partir de um quadro de longitudes que situa uma centena de cidades da M onarquia em relação ao meridiano da cidade de M éxico em vez de fazê-lo em relação ao meridiano de $M$ adri ou de Sevilha: por isso temos uma lista de localidades, começando pelas da N ova Espanha, do Peru, do Brasil, depois temos as da Espanha, das Filipinas e da "Gran China", para acabar com as cidades da Í ndia portuguesa: Calicute, Goa, D iu. A cada vez o cosmógrafo indica a diferença horária calculada entre a capital do M éxico e a cidade mencionada. Assim sabemos que Pernambuco fica a quatro horas e cinqüenta e oito minutos da cidade de M éxico, Bahia de Todos os Santos a quatro horas e quarenta e cinco minutos... Sob a pena e pelos cálculos do $\mathrm{H}$ einrich $\mathrm{M}$ artin, a cidade do $\mathrm{M}$ éxico torna-se como que um eixo histórico e um centro geográfico a partir do qual o tempo europeu torna-se o tempo ocidental. 
A vitória do tempo cristão, porém, está longe de ser absoluta. Com o tempo da I greja, chegou também na América, na Ásia ou na África o tempo judeu dos cristãos-novos. O utros cômputos, até nas zonas diretamente controladas pelo rei de C astela, resistiram à unificação do tempo na medida do possível. Em M anila, a capital espanhola das Filipinas, o bairro dos mercadores Sangleyes segue a hora chinesa, enquanto os cronistas indígenas da $\mathrm{N}$ ova $\mathrm{E}$ spanha continuam obstinadamente estabelecendo concordâncias entre os seus calendários e o dos cristãos. As maneiras indígenas de contar o tempo não deixaram indiferentes os espanhóis, como bem revelam os numerosos estudos feitos pelos missionários castelhanos sobre os cômputos mexicanos, assim como numa outra região do globo, as informações relativas aos milênios de história chinesa.

Pois, tempos e espaços cruzam-se e confrontam-se no seio da M onarquia e mesmo fora dela, já que a C hina imperial teve curiosidade pelos relógios europeus. Conviria exumar pouco a pouco esta trama tão complexa sem se limitar à perspectiva de uma ocidentalização conquistadora ou a uma visão dos vencidos impermeável às mudanças.

\section{0 "local" e o "global", a pátria e o mundo}

A circulação das novas drogas ilustra a maneira como o "local" consegue uma projeção, uma "visibilidade" súbita na escala "global", ou seja, em várias cenas, seja ela européia, americana e mesmo asiática. $0 \mathrm{~s}$ afrescos pintados pelos índios do M éxico mostram como elementos provindos do maneirismo internacional encontram-se com as tradições autóctones, ou melhor com os fragmentos delas que conseguiram sobreviver. É evidente que "local" e "global" são categorias contemporâneas, ainda muito mal definidas. $E$ também é evidente que não se trata de projetá-las sem defini-las e adaptá-las às sociedades dos séculos XVI e XVII. I sso, porém, não significa que o historiador tem que ignorar sistematicamente as solicitações do presente quando elas podem ajudar a reler o passado de maneira nova e a entender melhor as singularidades do nosso mundo contemporâneo.

D e fato, no seio da M onarquia, os testemunhos mais diversos distinguem duas esferas de atividade: aquela de onde se vem, e para onde por vezes se volta, e aquela na qual nos movemos. Localmente, é a "pátria" , o "pátrio ninho" que serve de ponto de ancoragem. É o lugar para o qual se volta depois de ter percorrido os mares e os continentes, "como o pássaro ausente do patrio ninho", enquanto o global seria o "mundo".

$\mathrm{N}$ ão é fácil definir termos como estes, menos ainda determinar a natureza dos laços que os unem. D urante o século XVI, a relação entre o que constituía o "local" - a pátria - e o que correspondia ao "global", o mundo, mudou constantemente na medida em que pátria e mundo tomaram outros sentidos. Estas mudanças estão estreitamente ligadas aos contínuos desenvolvimentos da expansão ibérica. Como se tratasse de dois processos paralelos e indissociáveis, a redefinição do "local" acompanhou a eclosão, a emergência de um "global" que se identifi- 
cava cada vez mais com o espaço planetário. Podemos nos perguntar como o pintor índio de Puebla podia conceber o "local" já que a sua cidade era uma fundação espanhola de apenas meio século. Q uanto ao "global", ele o tinha que imaginar povoado com criaturas tão estranhas como a centaura 0 cyrhoe e as sibilas que a acompanham ${ }^{7}$.

Ao mesmo tempo que se redefinia o "local", surgiu um espaço global, estendido à escala planetária. Com M agalhães e EI C ano, o mundo tornou-se um globo ao qual era possível dar a volta. Tornou-se uma realidade vivida e mensurável. As primeiras ligações regulares transpacíficas e o domínio progressivo dos itinerários planetários transformaram o excepcional numa prática rotineira, bem que ainda muito arriscada. A emergência desta nova dimensão - que se fez graças à relação marítima direta entre a Á sia e a América - precedeu de pouco a edificação da M onarquia católica. Assim, os progressos das técnicas de navegação, a herança da tradição imperial do 0 cidente latino, o expansionismo ibérico e a realização das ambições universalistas do cristianismo, favoreceram a difusão de uma outra visão do mundo, concebido como um conjunto de terras ligadas entre elas e colocadas sob uma mesma dominação. N esse contexto e nessa acepção, o termo "mundo" tornou-se comum nos textos da época ${ }^{8}$. Todos os cronistas da M onarquia católica e dos seus vizinhos começam as suas crônicas falando de um mundo que não é só aquele da criação, dos antigos e da I dade M édia, mas também o conjunto formado por quatro partes distintas - Europa, América, África, Ásia - ou seja, zonas distribuídas nos dois hemisférios e que já haviam sido ocupadas ou que deveriam ser rapidamente conquistadas.

O "global" corresponde também a uma visualização sempre mais aguda do globo terrestre. No século XVI, este último desvela-se na sua realidade física e na sua integralidade nos mapa-mundi, nas esferas armilares e nas tapeçarias?. $M$ as também podemos lembrar os escritos dos poetas ibéricos, que descrevem viagens feitas no ar sobre máquinas voadoras cujos passageiros descobrem:

[...] do Brasil os páramos incultos;

Os Andes, O Dorado e os temidos

D esertos do $D$ ariém, cheios de assaltos,

Embora então frescos e floridos...

\section{As relações do global e do local}

O s vastos espaços que cobrem a M onarquia convidam a multiplicar as perguntas. Como o local integra-se ao global tais como podemos definir estes termos na segunda metade do século XVI? Como os atores da época podem perceber o local no seio de uma dominação mundializada como a M onarquia católica? Como o "global" traduzia-se ou, antes, era percebido localmente no seio de um espaço concreto, vivido dia a dia?

M uitos indícios podem ser seguidos. A leitura de três autores da M onarquia, o calabrês Tommaso Campanella e os espanhóis estabelecidos no M éxico, 
Juan de Torquemada e Bernardo de Balbuena, traz indicações bastante interessantes. Embora as suas concepções do global e do local sejam muito diferentes, os três autores da M onarquia concordam em reconhecer a missão providencial da Espanha e imaginam o local como uma pequena sociedade ideal ou idealizada. Pode ser a cidade do M éxico, a comunidade indígena controlada pelos franciscanos ou a utópica Città del sole do calabrês C ampanella.

L onge de se reduzirem à afirmação da hegemonia castelhana, os sistemas de representação que encontramos no quadro da $M$ onarquia revelam que a unidade dinástica e religiosa é compatível com pontos de vista múltiplos que reservavam a cada região do império um papel dinâmico. Como se o pertencimento ao império nunca discutido pudesse se acomodar a uma releitura local, criadora e singular.

Poderíamos reler, na mesma perpectiva, a $\mathrm{R}$ hetorica christiana do mestiço mexicano D iego Valadés, publicada em Perugia no ano de 1579, ou examinar os Commentari os reales do I nca G arcilaso de la Veja, que coloca frente à M onarquia católica uma visão idealizada do reino dos Incas. Caberia também estender a análise aos autores portugueses para estudarmos os laços que estabelecem entre uma Lisboa posta no centro do mundo, e os gigantescos espaços da dominação filipina. Sem esquecer a Ásia portuguesa e a sua capital, Goa, chamada de "R oma da Ásia". Por fim, poderíamos interrogar um autor africano, o mulato André Alvarez de Almada, que nos deixou um Tratado breve dos rios de Guiné do C abo Verde, no qual define o lugar que deve ocupar a Guiné e o Brasil no contexto da M onarquia.

O que se observa então é que a partir das periferias da M onarquia, sejam napolitanas ou portuguesas, mexicanas ou peruanas, africanas ou asiáticas, nasceram simultaneamente representações do mundo que articulavam o "local" e 0 "global" sob múltiplas formas que podiam assumir no seio da M onarquia católica. O u quer dizer que em vez de só estudar o "olhar europeu" sobre o resto do mundo ou a "representação do O utro", preferimos considerar olhares e representações cruzados.

\section{Viver entre os mundos}

Estes indícios, no entanto, apenas indicados, só concernem a produções intelectuais. M esmo se pertencem a um quadro comum parecem revelar parentescos insuspeitados ou até hoje pouco analisados. Existe outra maneira de considerar estas questões. 0 estudo dos indivíduos pode desvelar a maneira como o local e o global são constantemente rearticulados, e só ao multiplicar os estudos de casos poderemos reunir informações significativas. Como nos exemplos anteriores, os casos arrolados a seguir só pretendem oferecer algumas pistas e idéias de pesquisa.

U ma característica bastante notável é o nomadismo dos homens da M onarquia. É evidente que este traço não apareceu com a M onarquia católica, mas 
a partir dela tornou-se muito mais comum. Como no M editerrâneo de Braudel, o movimento dos homens é o elemento que dá unidade ao gigantesco espaço aqui considerado, como, por exemplo, o nomadismo dos pintores europeus, que introduziram o $\mathrm{M}$ aneirismo nas quatro partes do mundo, em particular, na $\mathrm{N}$ ova E spanha do macaco $\mathrm{O}$ zomatli. $\mathrm{O}$ itinerário do pintor antuerpiano Simon Pereyns conduziu-o dos Países Baixos a Lisboa, depois à corte castelhana, em Toledo, para logo cruzar o Atlântico, chegar ao M éxico e lá percorrer toda a terra novohispânica. M uitas vezes, a realidade superava a ficção: se Guzmán de Alfarache, o protótipo do herói picaresco, circulou na Bacia do M editerrâneo ocidental, o seu criador, o escritor $M$ ateo Alemán, depois de ser publicado em Lisboa, cruzou o Atlântico e viveu vários anos na cidade do M éxico. Os deslocamentos efetuam-se fora das fronteiras da Europa ocidental e do mundo mediterrâneo: muitos homens, hoje bastante esquecidos, davam a volta ao mundo. Pedro O rdónez de C eballos lisonjeava-se de tê-lo percorrido várias vezes:

[...] desde esta idade de nove anos até os quarenta e sete anos, andei peregrinando e vendo o mundo, andando por ele mas de trinta mil léguas, tocando todas as cinco partes dele: Europa, África, Asia, América e M agalhánica.

No fim da sua vida, Pedro O rdónez acabou com o título de vigário-geral dos reinos da Cochinchina e de chantre da I greja de $\mathrm{H}$ uamanga no Peru.

$\mathrm{N}$ a mesma época, o franciscano $\mathrm{M}$ artín I gnacio de Loyola desempenhava atividades intensas de religioso, diplomata e homem de negócios em duas zonas do globo postas nas antípo das uma da outra: a Ásia de M anila, M acau e C antão por uma parte, e a América rioplatense por outra parte.

$A$ vida de $M$ anuel da Paz cruza também os espaços da $M$ onarquia. $N$ ascido em O linda " pertencia às comunidades cristãs-novas de Recife e $O$ linda, de onde saíram os primeiros luso-brasílicos globalizados", a expressão é de L uiz Felipe de Alencastro ${ }^{10}$. A família de $M$ anuel voltou para o Reino no final do século XVI, tendo o mesmo investido no negócio asiático e se estabelecido em Goa (16071616). Retornou a Lisboa e logo mudou-se para Madri, onde o seu palacete ficava defronte do Palácio real de Buen Retiro.

Estes deslocamentos não se faziam em sentido único. $\mathrm{N}$ ão podemos subestimar os itinerários que levaram para o continente europeu mestiços americanos como o I nca Garcilaso de la Vega e D iego Valadés, ou enviados japoneses, como os alunos dos jesuítas que visitaram Lisboa, M adri e outras cidades da Europa ocidental.

Convém perguntar sobre a representatividade destes casos que, todavia, podem ser facilmente multiplicados. $\mathrm{N}$ ão podemos evocar aqui, em poucas palavras, os conquistadores e os exploradores, os missionários e os eclesiásticos ou os mercadores, cujas vocações e cujos interesses conduziram para os demais continentes. Sem esquecer os escravos africanos que foram deportad os para a E uropa, 
a América ou a Ásia, muitas vezes depois de longos deslocamentos no continente africano, além do "degredados" do império português e dos "vagos" do império castelhano. $0 \mathrm{~s}$ vel hos reflexos eurocêntricos nos levam a repelir estas figuras nas sombras das periferias e na exceção. As coisas tornam-se distintas se fazemos da M onarquia, e não da E uropa ocidental, a nossa base de pesquisa e de observação.

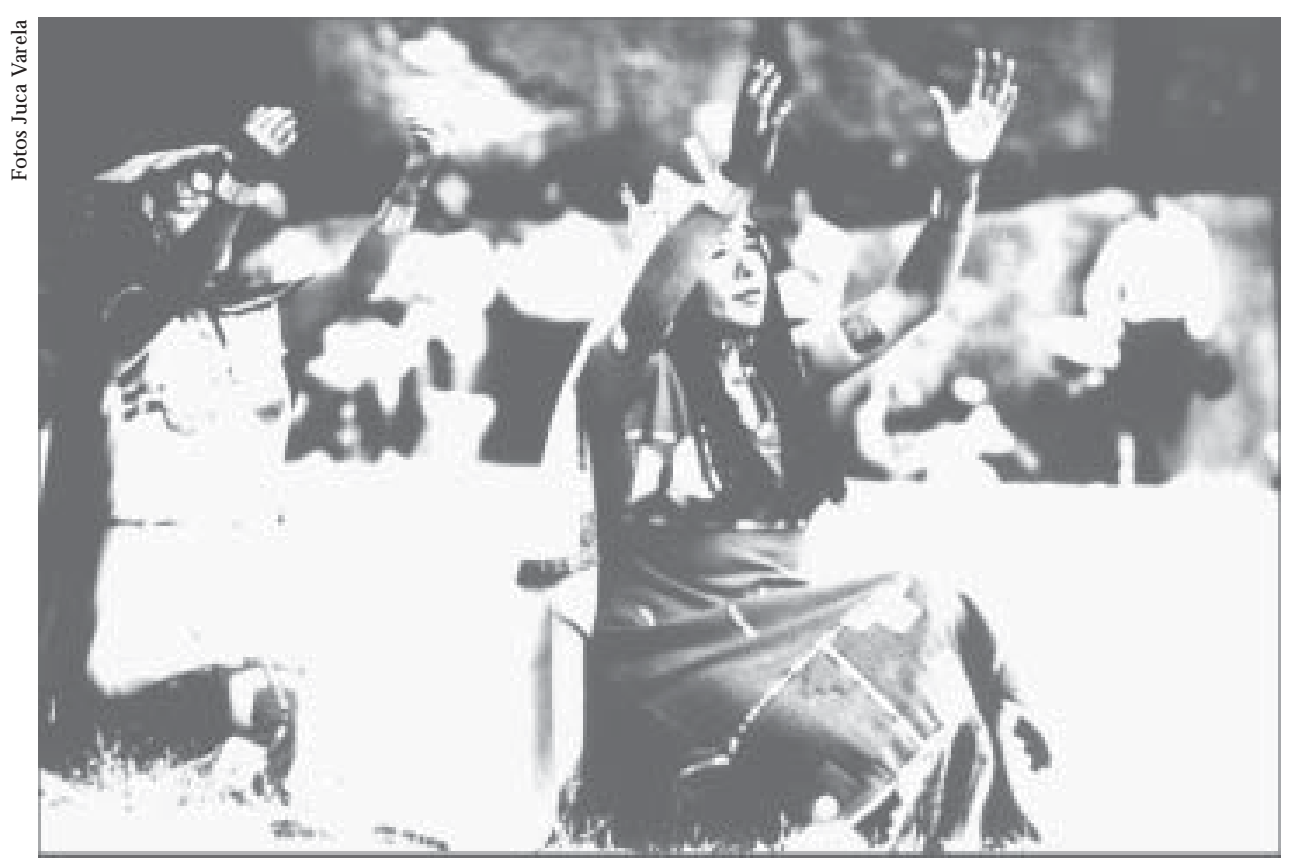

"A I greja explora os sincretismos cristãos para enraizar o culto católico..."

Por enquanto, parece maisimportante identificar em cada trajetória os novos comportamentos induzidos pela M onarquia através das suas dimensões planetárias: mobilidades intercontinentais, nomadismos, facilidade para deixar um lugar pelo outro, poder de adaptar-se a âmbitos variados a fim de circular sem obstáculos nos mundos da M onarquia etc. Conviria examinar de perto essa capacidade e essa propensão para circular de uma civilização a outra, relacionando-as com as notáveis facultades de observação que costumavam mostrar aqueles que faziam parte da M onarquia. $O$ relato do florentino $C$ arletti ou $A$ viagem do $M$ undo, do espanhol O rdónez de C eballos, são cheios de observações extraídas das sociedades e das línguas as mais diversas. A parecem hoje tão precisas e cuidadosas que tendemos a chamá-las de etnográficas. A pesar dos estereótipos, dos preconceitos e das segundas intenções das quais estes textos são repletos, esses ol hares revelam uma vontade contínua de acumular informações sobre a M onarquia e os seus vizinhos. Evidentemente, expressam um desejo de dominação e de conquista impulsionado dos centros da M onarquia, mas, ao mesmo tempo, traduzem a capacidade sistemática de se abrir aos demais: o texto de Bernardino de Escalante sobre a China examina o paradoxo desta: como é possível que um país tão perfeito seja idólatra? 0 jesuíta L uís F róis quer entender o porquê de os japoneses, tão civilizados, terem costumes diferentes daqueles dos portugueses. 
M as a adaptação pode ser efetuada de outros modos. $\mathrm{D}$ iz respeito tanto à alimentação, ao clima, ao corpo, às técnicas como à penetração das redes locais feitas numa escada planetária. Estas experiências não se limitaram aos meios intelectuais que nos deixaram testemunhos escritos. I mplicaram milhares de europeus e não-europeus que aprenderam a viver e a so breviver - no caso dos escravos africanos ou das massas ameríndias - entre vários mundos.

Q uais são as perguntas que podemos fazer aos homens da M onarquia? Essas perguntas são ao mesmo tempo simples e complexas: como conectar-se com a América? como conectar-se com a Europa? como viver entre dois mundos? 0 espaço falta para

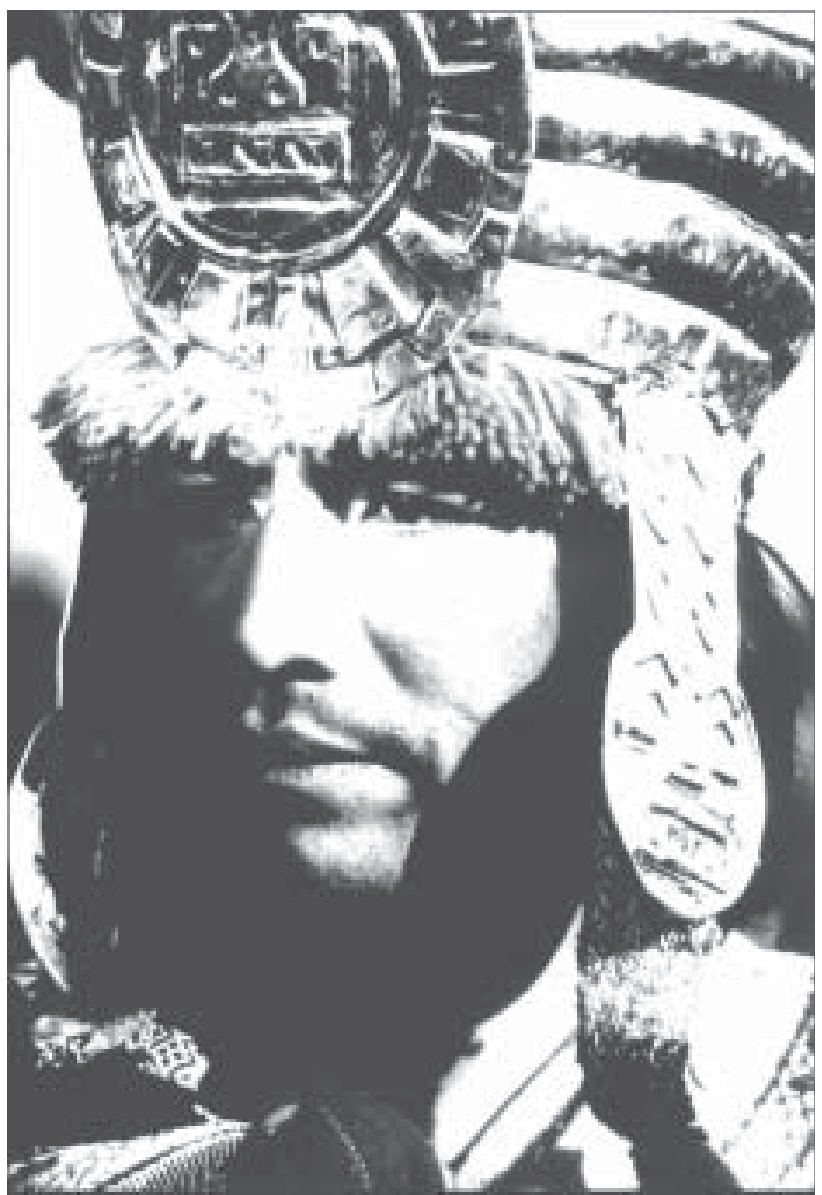

"A ocidentalização provoca mestiçagens..." examinar mais casos. M as o estudo da M onarquia não tem de se limitar aos indivíduos, mesmo se for necessário multiplicar os estudos de casos e as pesquisas de micro-história para analisar estes mecanismos de adaptação, transformação e invenção que proliferam em todos os âmbitos da M onarquia.

\section{M undialização e ocidentalização}

A mundialização ibérica abrange duas dimensões diretamente ligadas à difusão planetária da dominação ibérica: a ocidentalização e a globalização, so bre a qual voltarei em pouco tempo.

A ocidentalização designa todo um conjunto de empresas que procuram transformar a natureza, os seres, as sociedades e os imaginários dominados pela M onarquia católica. São estratégias complexas, múltiplas da dominação que se sucede a partir do século XV. A cristianização, a sujeição dos autóctones a uma dominação política ocidental, a urbanização de tipo europeu, a difusão do alfabeto latino, da imprensa e do livro, a exploração econômica são as manifestações, nem sempre coordenadas, do processo de ocidental ização. São empresas ruidosas e muitas vezes visíveis, espetaculares como a destruição dos antigos ídolos, a 
"guerra das imagens", os danos trazidos pelos deslocamentos das povoações indígenas, o trato maciço do negros, os efeitos deletérios da exploração dos homens e das sociedades locais.

Essas empresas de transformação são destruidoras. Q uem resiste é eliminado. Q uem é demasiado débil, fraco, desaparece. A chegada de novas doenças quase acabou com a povoação indígena do M éxico: dos 25 milhões que existiam no momento da chegada dos espanhóis, apenas 750 mil restariam um século mais tarde.

Porém, muitas vezes a ocidentalização provoca mesclas e mestiçagens, tais como:

- as mestiçagens biológicas: os mestiços do M éxico, os mamelucos do Brasil;

- as mestiçagens das línguas e das crenças;

- as mesclas dos saberes e das técnicas;

- a sobreposição e a imbricação das formas de organização do trabalho: 0 trabalho comunitário de origem pré-hispânica e as exigências do mercado espanhol; a conexão dos circuitos indígenas com os circuitos internacionais (o comércio do cacau, do anil etc.).

Em outros termos, a ocidentalização provoca, deliberadamente ou não, mestiçagens. A I greja explora os sincretismos cristãos para enraizar o culto católico. D o mesmo modo, a administração espanhola inventa compromisos, arranjos com as instituições autóctones.

Ao contrário, outras mesclas são reações de adaptação, de sobrevivência à dominação européia: constituem um coquetel de soluções para o negro e o índio poderem enfrentar a sociedade colonial.

\section{M undialização e globalização}

O estudo dos processos de aculturação e de globalização deixa na sombra outra dinâmica, mas sutil e, logo, mais perversa, muitas vezes equivocada com as precedentes (mundialização e ocidentalização) enquanto a sua maneira de enraizar a dominação ocidental aparece radicalmente diferente.

$\mathrm{N}$ um certo número de campos - todos ligados às formas e às expressões mais sofisticadas, estratégicas e elitistas dos saberes europeus - tais como a filosofia, a arte, a literatura -, tudo acontece como se o contexto extra-europeu e as suas caraterísticas singulares e sem precedentes pudessem não ser levadas em conta.

No caso da globalização, as idéias e as formas desenvolvem-se em esferas que parecem ser totalmente indiferentes aos lugares, impermeáveis às tradições locais e cegas às sociedades extra-européias.

A este fenômeno damos o nome de globalização, para distingui-lo de mundialização (que corresponde à difusão planetária dos traços) e da ocidentalização (que nasce do confronto, do enfrentamento com realidades extra-européias). 
O sistema e o ensino universitários, os quadros e os mecanismos conceituais, as normas jurídicas, as linguagens formais e simbólicas são os espaços privilegiados, todos essenciais, do processo de globalização no século XVI.

Em outros termos, e coloco de maneira muito esquemática, a universidade do M éxico, o sistema aristotélico e os Emblemas de Alciati foram alguns dos maiores vetores da mundialização na M onarquia católica.

Ao comparar a difusão do aristotelismo nas universidades das Í ndias ocidentais, nos colégios jesuíticos da América, da África e da Ásia, podemos observar que não apenas o corpo da doutrina filosófica permanece intacto, mas que os novos desco brimentos - a questão das antípo das e da zona tórrida que a contradizem formalmente - ficaram integrados de tal maneira que perderam qualquer fermento desestabilizador.

A globalização segue um esquema comum. Seus processos desenvolvem-se de acordo com um esquema uniforme:

- um desdobramento planetário, uma extensão nas quatro partes do mundo, que se integra à trajetória da globalização;

- um enraizamento local que acompanha as etapas da ocidentalização;

- uma interacão regular com as bases européias;

- uma homologação contínua: as produções extra-européias devem ser constantemente validadas, legitimadas pelos centros europeus: por exemplo, a publicação em Europa dos escritos filosóficos ou literários dos europeus estabelecidos na América;

- uma indiferença às idéias, às formas e às expressões de origem autóctone;

- uma propensão ou uma tendência sistemática a transformar e a converter o que era europeu em ocidental: processo que corresponde a um tipo de ocidentalização distinta da anterior, já que não ocidental iza o mundo exterior mas produz o ocidental.

I sso quer dizer que a global ização se caracterizaria pelo seu encerramento, a sua impermeabilidade, o seu caráter estanque? Como explicar, no entanto, que esferas inteiras da tradição ocidental sejam aferrolhadas? Trata-se apenas de um fenômeno colonial que manifesta a sujeição da periferia ao centro europeu hegemônico, ou devemos considerar que a globalização é o resultado de uma censura explícita, ou ainda a conseqüência da rigidez própria da tradição ocidental de saberes, idéias e formas?

Parece que estamos frente a um fenômeno de hegemonia ideológica particular. Sob a estratégia frontal de ocidental ização organiza-se outra estratégia que a completa e a reforça, pois impede, do coração mesmo da tradição ocidental, a difusão de vias alternativas, de modos de pensar ou de estilos diferentes: ou seja, qualquer forma de pensamento alternativo nascida localmente tem que ser circunscrita ao local ou violentamente erradicada. I sso por que as culturas mestiças que proliferam em resposta à ocidentalização estão condenadas a ocupar territórios limitados sem contato entre eles. 
O s produtos mestiços podem cruzar os oceanos apenas se são neutralizados e exotizados. I sso poderia explicar o porquê de não encontramos quase nenhuma circulação entre os sincretismos mexicanos e os andinos, ou porque tão poucas formas sincréticas africanas encontram-se na cidade de Lisboa no século XVIII. Ao contrário, os objetos mexicanos que chegaram à Europa como os mosaicos de plumas, tiveram muito êxito, uma vez que faziam parte dos cabi nets de curiosités

I sso é o que se observa hoje no âmbito da cinematografia. Ao cinema de $\mathrm{H}$ ollywood, que funciona conforme esquemas estritamente definidos e impositivos, opõem-se as cinematografias locais. 0 primeiro impõe uma visão do mundo uniforme e sob esta visão uma ordem visual; estamos no campo da globalização. As outras cinematografias, no I rã e na China, mesclam as influências ocidentais, européias e hollywoodianas com as suas próprias tradições e os seus próprios passados. Enfrentam, encaram a ocidentalização a qual me traz respostas muito diferentes.

\section{O s mundos misturados da M onarquia}

Submetidas as duas formas da mundialização ibérica - a globalização e a ocidentalização -, as terras da M onarquia são quase todas de mesclas, de confrontos e de conflitos. São também limites sempre em contato com outros universos, que poderiam submetê-los: os turcos, a Í ndia, a China ${ }^{11}$. As suas fronteiras não são impermeáveis: os portugueses da Ásia saíam da zona de controle de L isboa e circulavam facilmente nas outras sociedades: eram os portugueses "fora do império" para usar o título de um trabalho de A. J. R. Russel-Wood ${ }^{12}$.

Estas múltiplas sociedades mestiças podem ser abordadas de várias maneiras. A mais simples e talvez a mais limitada consiste em repertoriar e explorar as mestiçagens biológicas ${ }^{13}$. Podemos dar um passo mais adiante ao estender a categoria de mestiços a to dos os indivíduos que assumem o papel de passeurs entre as so ciedades e entre os grupos. Eles podem ser europeus ou não-europeus, ou seja, ameríndios, africanos e asiáticos. Podemos dar outro passo mais à frente ao estudar a maneira como os europeus americanizam-se, africanizam-se ou oriental izam- $\mathrm{se}^{14}$. O s portugueses do Brasil tornaram-se os brasílicos, os de Angola os angolistas. N a obra de Ambrósio Fernandes Brandão, os "reinóis" opõemse aos "brasilienses" tal como os recém-chegados se distinguem dos que contavam muitos anos de vida e experiência naquelas terras.

A pesquisa torna-se ainda mais interessante se, superando a etapa dos inventários e das descrições, procuramos entender o funcionamento e as especificidades das so ciedades que apareceram em âmbitos tão distintos como no M éxico, nos A ndes, no Brasil, nas costas africanas, na Í ndia, no J apão e nas Filipinas. Por muito tempo, uma maneira de deixar de lado este problema foi chamar estas realidades de "coloniais". M as as coisas complicam-se se aceitamos que a relação "colonial" - que coloca estas sociedades numa posição de dependência 
política e de exploração econômica em relação a uma metrópole - não é mais do que uma dimensão entre outras que caracterizam os mundos da M onarquia. M uitas vezes, as suas capacidades de autonomia, de reação e de invenção foram subestimadas. De fato, estas sociedades "coloniais", que na maioria dos casos foram sociedades urbanas, parecem tanto mais singulares quanto procuram articular modos de vida e de expressão, formas de organização social e tipos de presença ocidental radical mente distintos. D esta situação resultam sistemas compostos de dominação e de organização do trabalho, associações de saberes e de técnicas de origem muito diversas, representações híbridas do espaço e do tempo, mesclas de crenças. $\mathrm{N}$ ão só os corpos se misturam, mas todas as formas da existência social e do pensamento.

Complexidade e diversidade destes mundos: o inventário das grandes cidades mestiças da M onarquia católica mostra que cada lugar tem o seu destino particular: a cidade do M éxico não é Lima, tampouco Lima confunde-se com Potosí nem com Salvador da Bahia.

\section{0 macaco, a centaura e o político}

A mestiçagem, contudo, é sempre muito mais do que uma bricolagem cultural. Ela tem uma dimensão política. Parece-me que o termo "mestiçagem cultural" é pouco como uma armadilha, uma vez que as mestiçagens são sempre políticas. O s índios pintores que inventaram o encontro do macaco com a centaura tinham um objetivo preciso na mente. Em primeiro lugar, procuravam conseguir para o seu passado religioso o estatuto privilegiado que a mitologia greco-romana tinha face ao cristianismo, ou seja, o estatuto de um paganismo tolerado e valorizado; e, em segundo lugar, queriam construir para si mesmos uma relação aceitável com o passado ameríndio em vez de terem que interiorizar a ruptura radical que impunha a cristianização, em vez de viverem uma situação continuamente esquizofrênica.

Assim, O zomatli e O cyrhoe nos interpelam uma vez mais. Q ual pode ser a relação entre as mestiçagens e o político? 0 macaco e a centaura nos convidam a examinar a maneira como o político influi sobre as manifestações locais da mestiçagem. M as já que todas estas misturas são produzidas no espaço da M onarquia católica, o assunto não pode ser reduzido às suas dimensões locais, nacionais ou coloniais. Contudo, a dominação política, social e econômica exercida pela M onarquia não basta para explicar a dinâmica destes fenômenos, presentes nos quatro continentes. Seria postular uma relação de causa-efeito um pouco simples demais. D e fato, parece-me mais interessante considerar a dominação da M onarquia através do jogo complexo da ocidentalização e da globalização que acabamos de definir. Além disso, a esta dimensão convém acrescentar outro elemento: a dimensão planetária e "interativa" assim criada. A penas a existência da M onarquia instaura espaços de circulações, intercâmbios e conflitos que escapam a qualquer estratégia global, por ambiciosa que seja. 
Por estas razões, o global que se manifesta na M onarquia não pode ser confundido com uma estratégia global de dominação que se enfrentaria com uma multidão de "histórias locais", mesmo se a I greja, a Coroa, as administrações e as economias ibéricas intervieram muito nos domínios que nos interessam aqui ${ }^{15}$.

A análise das mestiçagens na M onarquia católica nos obriga a superar as frágeis fronteiras das disciplinas e das áreas culturais tradicionais. Convida-nos também a buscar no contato com as ciências duras, como a teoria da complexidade, categorias e métodos novos para poder "pensar o mundo". São alguns dos desafios que nos apresenta o novo milênio e que, à sua maneira, nos lembram 0 macaco mexicano e a centaura européia.

\section{N otas}

$1 \mathrm{E}$ ainda o caso do livro recente de G eoffrey Parker, The World is not Enough. The Grand Strategy of Philip II, o qual, apesar do título e das suas ambições, contém poucas coisas so bre os aspectos africanos, asiáticos e americanos da M onarquia. Acontece 0 mesmo com as abordagens italianas, que não levam em conta as Américas ibéricas, Portugal e Ásia em suas reflexões sobre o "sistema imperiale".

2 Traduzidas para o nahuatl no $M$ éxico e para o japonês em $N$ agazaki, as Fábulas, de E sopo, tornaram-se acessíveis às elites japonesas e indígenas da N ova Espanha.

30 desenvolvimento das cartografias européias acompanha-se de um interesse por outras cartografias, trate-se do uso sistemático das pinturas dos tlacuilos indígenas no M éxico ou da curiosidade ibérica pelos mapas chineses: no seu Di scur so sobrea C hina, - galego Bernardino de Escalante (1577) escreve "N uma carta geográfica feita pelos mesmos Chineses que se trazou a Portugal em poder de J uan de Barros, historiador dotíssimo daquela nação, estão assinaladas duzentas e quarenta e quatro cidades famosas".

4 F. Bethencourt e K. Chaudhuri, H istória da expansão por tuguesa, Lisboa, Círculo de Leitores, 1998, t. II, pp. 490-491.

5 I dem, p. 491.

6 As circulações intelectuais também foram intensas entre Portugal e C astela. 0 primeiro livro espanhol dedicado à China, o D iscurso de la N avigación (1577), escrito pelo galego Bernardino de Escalante, utiliza as informações contidas nas crônicas portuguesas, como as D écadas de J oão de Barros, além de explorar contatos diretos do autor com os meios lisboetas portugueses e chineses. As obras mestras do I nca $\mathrm{G}$ arcilaso de la Vega são publicadas em Lisboa.

7 Assim, na América, a conquista espanhola obrigou os invasores e os vencidos a redefinirem o "local". Com o passar dos anos e a distância, os laços dos conquistadores com as suas comunidades de origem na península esticaram-se ou desfizeram-se. N este meio tempo apareceu um "neo-local" americano que se apresentou como uma realidade institucional. A fundação da cidade de Veracruz pelos conquistadores em 1519 materializa e oficializa esta reterritorialização de tipo castelhano no solo do N ovo M undo. D o lado dos vencidos, tanto a criação das "repúblicas de Índios", que foram o resultado da articulação das instituições ibéricas com as tradições ameríndias, como a política das "congregações" provocaram um processo paralelo de "relocalização" no seio das 
comunidades indígenas. No caso de Brasil, a origem da forte ligação entre a família de Sá e o Rio de J aneiro está nos laços familiares e clientelares estabelecidos ao longo do século XVI e do século XVII. F. Bethencourt, op. cit., t. II, p. 333.

8 Q uando descreve a difusão das novas espécies de plantas, o médico M onardes não pôde evitar usar sistematicamente esta palavra: "o uso delas difundiu-se não só na nossa Espanha mas também em todo o mundo". O cosmógrafo alemão estabelecido no M éxico, H einrich M artin, nunca perde de vista "as outras partes do mundo". N a Città del sole de T. C ampanella, o informante genovês lisonjeia-se de conhecer "tutto il mondo". Ambrósio Fernandez Brandão descreve o Brasil como a "praça do mundo" (Bethencourt, op. cit., t. II, p.491).

9 Assim, por exemplo, na tapeçaria realizada por Bernard Van O rley que mostra "A terra protegida por Júpiter e por Juno", vemos o império português nas suas dimensões brasileiras, asiáticas e africanas, representado sobre um globo branco e azulado de grande beleza.

10 Alencastro, 0 tratado dos viventes. Formação do Brasil no A tlântico sul, São Paulo, Companhia das L etras, 2000,103.

11 Estas sociedades híbridas superam as fronteiras da M onarquia. Os "piemonts" amazônicos tinham relações com as selvas que, apesar de serem aparentemente desconhecidas e hostis, não impediam os contatos e as trocas entre índios, mestiços, mamelucos e europeus.

12 As cidades de $\mathrm{M}$ acau e $\mathrm{N}$ agazaki pertencem a sistemas políticos distintos e vivem na encruzilhada de distintas civilizações.

13 Incita a examinar em todas as partes a aparição de novos grupos que chamamos de mestiços: mestiços e janizeiros da América espanhola, mamelucos do Brasil, mestiços da Índia, tangomaos da África etc.

14 Por exemplo, os espanhóis que se americanizam são chamados de indianos pelos moradores da metrópole. O s portugueses que se orientalizam são chamados de castiços ou indiáticos na Índia portuguesa.

15 Por isso, é necessário explorar esta trama em toda a sua complexidade e numa perspectiva que se parece com a dos especialistas da World H istory quando tratam "as partes do mundo" como zonas interconnected and interactive. A M onarquia católica oferece um exemplo perfeito de interactivezone, onde proliferam as relações entre os poderes, os grupos e as culturas.

\section{Referências biliográficas}

ALEN CASTRO, Luiz Felipe de. O trato dos viventes. Formação do Brasil no A tlântico sul. São Paulo, Companhia das L etras, 2000.

AL LEN, Paul C. Philip III and thePax hispánica, 1598-1621. N ew H aven, Yale U niversity Press, 2000.

BERNARD, Carmen e GRUZINSKI, Serge. H istoire du N ouveau M onde. t. II. Les métissages. Paris, Fayard, 1993.

BETH ENCOU RT, Francisco e CH AU DHURI, K. (dirs.). H istória da expansão portuguesa. Lisboa, Círculo dos Leitores, 1998. 
BRAU DEL, Fernand. La M éditerranée et le mondeméditerranéen à l'époque de Philippe II , t. III. Paris, Armand Colin, 1990.

CHAU NU, Pierre. "L'expansion européenne du XIIle au XVe siècle", N ouvelle Clio 26. Paris, PU F, 1969.

. "Conquête et explotation des N ouveaux M ondes", N ouvelle Clio 26bis. Paris, PUF, 1969.

ESCALANTE, Bernardino de. Discurso dela navegación quelosPortugueseshazen a losrénos y provincias de oriente y de la noticia que se tiene de las grandezas del reino de la China, Séville, Viuda de Alonso Escrivano, 1577 (U niversidad de C antabria, Laredo, 1991).

GRU ZI N SKI, Serge. La col onisati on del'imaginai re Soci étésindigèneset occi dentalisation dansle M exique espagnol. XVI eX VIII e siècle Paris, Gallimard, 1988.

- La guerre des images de Christophe Colomb à Blade R unner, 1492-2019, Paris, Fayard, 1990.

- La pensée métisse. Paris, Fayard, 1999.

M ARTÍ NEZ, H enrico. R epertorio de lostiemposy historial natural desta N ueva España. M exico, H enrico M artínez, 1606.

M I G N O L O, Walter D. Local H istoried/ Global D esigns C ol oniality, Subaltern K nowledges and Border Thinking. Princeton, Princeton U niversity Press, 2000.

PARKER, Geoffrey. TheWorld isnot enough. Thegrand Strategy of Philip II. N ew H aven, Yale U niversity Press, 1998.

SU BRAH M AN YAM, Sanjay. ThePortugueseEmpirein A sia 1500-1700. A Political and Economic H istory. L ondon, Longman, 1993.

. "Connected H istories: N otes Towards a Reconfiguration of Early M odern Eurasia", em LIEBERMAN, Victor (ed.). Beyond Binary Histories Reimagining Eurasia to C. 1830. Ann Arbor, The U niversity of M ichigan Press, 1997, pp. 289-315.

Serge Gruzinski é professor do Centro N acional de Pesquisa Científica (CNRS) da É cole des H autes Études en Sciences Sociales, Paris. Tem livros traduzidos no Brasil, entre eles: A C olonização do imaginári o: Soci edadesindígenaseoci dentalização no M éxi co espanhol, Séculos XVI eXVIII (Companhia das Letras), A passagem do século 1480 1520: A sorigens da globalização (Companhia das L etras), R i o del anei ro, C i dade mestiça: N ascimento da imagem de uma nação (Companhia das L etras) e H istória do N ovo Mundo, v. 1 (Edusp).

Conferência feita pelo autor no Auditório do D epartamento de Antropologia da FFLCH U SP em 15 de setembro de 2002. R evista pelo autor. 